\title{
Regional Neuroscience Research Collaboration: The Alabama Experience
}

\author{
Kevin A. Roth \\ Robert and Ruth Anderson Professor and Chair, Department of Pathology, \\ University of Alabama at Birmingham; Director, Alabama Neuroscience Blueprint \\ Core Center
}

The Alabama Neuroscience Blueprint Core Center was established in
2006 as one of four Neuroscience Blueprint Interdisciplinary Center
Core Grant (P30) Program awardees. The Centers were awarded based on their ability to meet the needs and unique requirements of their local and regional neuroscience research communities. The Alabama Neuroscience Center, which is housed at the University of Alabama at Birmingham (UAB), is designed to facilitate interdisciplinary investigation of nervous system function and dysfunction through a multi-dimensional analysis of genetically modified rodents and other small animal models. The Alabama Neuroscience Blueprint Core Center has rapidly met its original goals and now serves in support of neuroscientists at UAB and participating institutions throughout the Deep South. The establishment of this regional neuroscience research center has had a transformative effect on the neuroscience community at UAB and participating institutions and may serve as a model for other regional research efforts.

Introduction: Planning for the Alabama Neuroscience Blueprint Core Center began in 2005 shortly after the release of the Neuroscience Interdisciplinary Center Core Grant RFA announcement NS-06-003. Fortuitously, this RFA coincided with the preparation and submission of a strategic plan for neuroscience growth at UAB to the Dean of the School of Medicine in October, 2005. It was immediately apparent that there were many striking parallels between the goals of the RFA and the goals for neuroscience research at UAB. Following a series of small group meetings to define the focus of the P30 application, NIH funded neuroscience investigators throughout Alabama, Mississippi, and Louisiana were contacted by e-mail or phone and encouraged to participate in the application. Based on our review of the needs of the regional neuroscience community, we proposed to establish the Alabama Neuroscience Blueprint Core Center at the University of 
Alabama at Birmingham. The original application included approximately 50 investigators from UAB, Southern Research Institute, Auburn University, University of Alabama, Tulane University, Louisiana State University, and University of South Alabama.

Neuroscience Blueprint: The P30 program that funds our center arose as a component of the NIH Blueprint for Neuroscience Research. This program is sponsored by 16 NIH Institutes, Centers, and Offices and is designed to focus on cross-cutting neuroscience activities, communicate best practices, and coordinate the planning and funding of research and development tools as well as neuroscience education, training, and career development. Together, these institutes provide approximately $\$ 5$ billion in NIH funding for neuroscience research with the two largest participating NIH Institutes being the National Institute of Neurological Diseases and Stroke (NINDS) and the National Institute of Mental Health (NIMH).

The Center Core Grant (P30) Program was designed to create a novel approach for funding core resources that would breach interdisciplinary boundaries and promote a team approach to neuroscience discovery. The program emphasizes developing effective infrastructure and addressing regional neuroscience needs. Budgets were capped at \$1.5 million per year in direct costs per application and applicants were encouraged to utilize existing institutional resources to enhance new core development. In addition to the Alabama Neuroscience Blueprint Core Center, three other centers were funded (La Jolla Neuroscience Center Core at the Burnham Institute; Neuroscience Center Core at the University of Minnesota and Mayo Clinic; and the Washington University Neuroscience Blueprint Interdisciplinary Center Core).

The Alabama Neuroscience Blueprint Core Center was awarded \$8.6 million and began operations in September, 2006. The over arching goal of our Center is to facilitate interdisciplinary investigation of nervous system function and dysfunction through the use of genetically modified experimental animals. The increasingly sophisticated ability to regulate gene expression levels across cellular and temporal domains and to monitor gene expression at the cellular level in living animals and brain slice preparations ex vivo provides an unprecedented opportunity to advance our understanding of the neurosciences. To traverse this spectrum of techniques requires cooperation and talents of numerous scientists and is typically beyond the capabilities of individual laboratories. The Alabama Neuroscience Blueprint Core Center has five scientific cores: Molecular Engineering; Cellular and Molecular Neuropathology; Neuroimaging; In Vivo Physiology and Phenotyping; and Cellular and Synaptic Physiology; as well as an Administrative Core (http://www.alneurosciencecenter.uab.e $\underline{\mathrm{du}})$.

The Center has been remarkably successful and as of May 2009, over 50 manuscripts have acknowledged our assistance, including publications in Science 1, Nature Medicine 2, Nature 
Neuroscience 3, and Journal of

Neuroscience ${ }^{4-7}$. These publications include authors from greater than ten Southern Universities and approximately thirty United State's and international institutions demonstrating that the impact of our award has been felt well beyond the borders of Alabama.

Metrics of Success: The establishment of the Alabama Neuroscience Blueprint Core Center has been transformative for the neuroscience community at UAB. By providing new interdisciplinary core resources and external "validation" of the exciting neuroscience investigations at $\mathrm{UAB}$ and other participating institutions, there has been rapid and compelling growth of neuroscience-related research and educational activities in Alabama. The following is a partial list of direct and indirect consequences of our Blueprint award:

- Between 2005 and 2008, the number of NIH Neuroscience Blueprint affiliated awards increased from approximately 200 to almost 300.

- NIMH funding increased $112 \%$, NINDS funding by $78 \%$, and NIA funding by $33 \%$ between 2005 and 2008.

- The Alabama Neuroscience Blueprint Core Center affiliated UAB Comprehensive Neuroscience Center (Dr. Kevin A. Roth served as inaugural Director) was awarded full University-wide Interdisciplinary Research Center status by the University of Alabama Board of Trustees in 2008.
- A new Undergraduate major in Neuroscience was approved by the University of Alabama Board of Trustees and its first class enrolled in 2009.

- UAB has experienced a net increase of approximately 40 new faculty in neuroscience-related tenure track positions since 2006.

In total, the impact of this award is now being demonstrated by increased number of NIH awards, more manuscripts being published in high impact scientific journals, new neuroscience-related training grants, and submission of interdisciplinary neuroscience grant applications involving investigators from multiple Alabama and regional institutions. The joint development and operation of the Alabama Neuroscience Blueprint Core Center and the UAB Comprehensive Neuroscience Center will hopefully, be a model for now neuroscience-related clinical care, research and education can be organized and maximally facilitated through an interdisciplinary, multiinstitutional approach.

Looking Forward: The Alabama Neuroscience Blueprint Core Center and $\mathrm{UAB}$ remain committed to the growth of regional neuroscience. To accomplish this goal we must remain focused on effective communication and collaboration. Through these efforts we hope to obtain a better understanding of neurological and psychiatric disease pathogenesis and to use this knowledge to develop new treatments and cures for nervous system disorders.

Acknowledgements: I'd like to thank Dr. Tom Miller (Office of Translational Research, NINDS, 
$\mathrm{NIH}$ ) and the UAB Neuroscience Community for many helpful discussions and their unmatched enthusiasm for neuroscience investigation. The Alabama Neuroscience Blueprint Core Center is supported by NIH Grant NINDS P30 NS57098.

\section{References}

1. Yang, Q, She, $\mathrm{H}$, Gearing, $\mathrm{M}$, Colla, E, Lee,M, Shacka,JJ, Mao,Z. Regulation of neuronal survival factor MEF2D by chaperone-mediated autophagy. Science 2009; 323(5910):124-127.

2. Isbell,TS, Sun, CW, Wu,LC, Teng, $\mathrm{X}$, Vitturi,DA, Branch,BG, Kevil,CG, Peng,N, Wyss,JM, Ambalavanan,N, Schwiebert,L, Ren,J, Pawlik,KM, Renfrow,MB, Patel,RP, Townes, TM. SNO-hemoglobin is not essential for red blood cell-dependent hypoxic vasodilation. Nat.Med. 2008; 14(7):773777

3. Hojjati,MR, van Woerden,GM, Tyler,WJ, Giese,KP, Silva,AJ, Pozzo-Miller,L, Elgersma,Y. Kinase activity is not required for alphaCaMKII-dependent presynaptic plasticity at CA3-CA1 synapses. Nat.Neurosci. 2007; 10(9):11251127

4. Habela,CW, Olsen,ML, Sontheimer,H. $\mathrm{ClC} 3$ is a critical regulator of the cell cycle in normal and malignant glial cells. J.Neurosci. 2008; 28(37):9205-9217.

5. Scheiderer,CL, Smith,CC, McCutchen,E, McCoy,PA, Thacker,EE, Kolasa,K, Dobrunz,LE, McMahon,LL. Coactivation of $\mathrm{M}(1)$ muscarinic and alpha1 adrenergic receptors stimulates extracellular signal-regulated protein kinase and induces long-term depression at CA3-CA1 synapses in rat hippocampus. J.Neurosci. 2008; 28(20):5350-5358

6. Mathew,SS, Pozzo-Miller,L, Hablitz,JJ. Kainate modulates presynaptic GABA release from two vesicle pools. J.Neurosci. 2008; 28(3):725-731

7. Shacka,JJ, Klocke,BJ, Young, $C$, Shibata,M, Olney,JW, Uchiyama, Y, Saftig,P, Roth,KA. Cathepsin D deficiency induces persistent neurodegeneration in the absence of Bax-dependent apoptosis. J.Neurosci. 2007; 27:2081-2090 